\title{
Integrated Enterprise Resilience Architecture Framework for Surviving Strategic Disruptions
}

\author{
Hassan Ahmed Hassan ${ }^{1, *} \&$ Galal Hassan Galal-Edeen ${ }^{1}$ \\ ${ }^{1}$ Faculty of Computers and Information, Cairo University, Egypt \\ *Correspondence: Faculty of Computers and Information, Cairo University, Egypt. E-mail: \\ hassan.hbarakat@gmail.com
}

Received: September 28, 2017 Accepted: October 21, 2017 Published: November 25, 2017

doi: 10.5296/erm.v4i1.13715 URL: https://doi.org/10.5296/erm.v4i1.13715

\begin{abstract}
Resilient business enterprises are able to survive strategic disruptions like technology disruptions and come back more successful. They succeed because they develop and effectively implement the resilience strategies of mitigation, adaption, and transformation. This paper proposes an integrated resilience framework that is based on a combination of enterprise architecture and business architecture frameworks. At the core of the proposed framework is a meta-model and a method. The framework guides the development of a unified vision of how a business enterprise can address a specific strategic disruption and transform itself in a successful way. The framework articulates the vision through the lens of business blueprint views that guide the formation of transformation initiatives. Through the mapping capabilities of the framework, the transformation initiatives cross over the boundaries between organization structures and domains. In the last section we demonstrate our proposed method and meta-model with the help of a case study.
\end{abstract}

Keywords: disruption; strategic disruption; resilience; mitigation; adaptation; transformation; operating model; competitive strategy; business model; enterprise architecture; business architecture; capability; value stream; value proposition; 


\section{Introduction}

We live in a world of change and disruptions. When they happen, the typical response is, "Who would have thought this will happen?". Whether the economy is strong or weak, competition is fiercer than ever and change comes faster than ever; and if a business wants to survive difficult times, it has to prepare itself to be able to make the right shift at the right time in response to disruptions and changes (Bossidy and Charan, 2002).

Disruptions can be rooted in new technologies, new disruptive business models, emergence of new regulatory and market forces, or changes in the availability of resources (Fiksel, 2003). Some of these disruptions can be game-changing phenomena causing storms that threaten the business enterprises going through those storms. These kinds of disruptions are called strategic disruptions (Schwartz and Randall, 2007). An example of such a strategic disruption is the digital photography technology that threatened the core businesses of two global enterprises, Fujifilm and Kodak (Komori, 2015).

Business enterprises going through these kinds of storms are not equal in their approach to dealing with them and ended up with different results after going through the storms; some succeeded while some failed. For example, Fujifilm succeeded while Kodak failed in facing the digital photography disruption (Komori 2015). EMC succeeded in facing the disruption of the new storage technologies and customer preference change in favour of low tier low cost storage solutions, while Sun Microsystems failed in facing the disruption of the technology bubble burst and the associated change in customer preference in favour of open low cost solutions (Bossidy and Charan, 2002).

Most often, business enterprises are able to identity the threat of strategic disruption. Kodak identified the threat of digital photography long time ago but failed to transform its business in response to the disruption (Komori, 2015). In contrast, Fujifilm redesigned leveraging its core competencies and targeted acquisitions with synergetic or transformational intent (Komori, 2015). In the same line, many current business enterprises see the emerging digital technologies including social, mobile, big data and analytics, IOT, AI, machine learning, cloud computing, and blockchain technologies; as threatening their profitability and even the survivability of their businesses. They also see these technologies present opportunities to offer new, compelling value propositions that combine their existing competencies with the capabilities of the new technologies.

The difference between successful and unsuccessful enterprises is that successful enterprises build resilience capabilities to prepare for strategic disruptions using resilient strategies (Hamel and Välikangas, 2003). A resilient strategy is not concerned with stabilizing business enterprises quickly under small shocks, but rather, it is concerned with making business enterprises continuously survive large strategic disruptions in the long term. A resilient strategy is concerned with surviving different strategic disruptions through continuously monitoring, interpreting, and adapting to sustainable trends that cause business enterprises to permanently lose the profitability and growth of their core businesses (Hamel and Välikangas, 2003). 


\section{Macrothink}

\subsection{What is Resilience and What Is Resilience Strategies?}

Resilience (with its roots in the Latin word resilio) means to adapt and "bounce back" from a disruptive event (Longstaff, Armstrong et al. 2010). Similarly, it is the capacity of a system to absorb disturbance, undergo change, and retain the same essential functions, structure, identity, and feedbacks (Holling 1973).

Within the resilience view, a system like a business enterprise, can exist in one of several basins of attractions called regimes. The system shifts from one basin of attraction or regime to another if it passes the threshold of a controlling variable (Holling 1973).

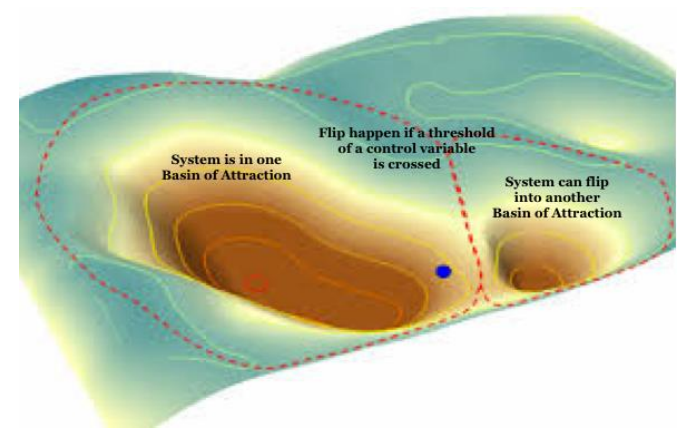

Figure 1. Basin of Attractions

A threshold of a controlling variable, is the level or amount of a change of that controlling variable, that causes a change in a critical feedback, causing the system to self-organize along a different trajectory towards a different attractor (Walker and Meyers 2004). Despite the fact that complex adaptive systems like business enterprises are affected by many variables; they are usually driven by only a handful of key controlling variables (Walker and Meyers 2004). This is an important concept that is used to create and execute strategies to respond to disruptions. For example, if we want to prevent the system from flipping into another regime, we should prevent crossing the thresholds of the systems' controlling variables.

(Folke, Carpenter et al. 2002) introduced three kinds of resilience strategies; mitigation, adaptation, and transformation.

Mitigation strategy is the capacity to initiate counter forces to keep the control variables checked within their thresholds or delay crossing these thresholds. This will prevent or delay the expected impactful changes in the structure and critical feedback which causes the system to flip into an alternate undesirable stability regime of that system (Walker and Meyers 2004).

Adaptation strategy represents the capacity to adjust responses to changing external drivers, controlling variables and internal processes, and thereby allow for return to the current trajectory (stability domain). It takes the system into a temporary recovery state in which adaptive responses work to cross back the control variables thresholds, return back to the current regime, and try to move away from the control variables thresholds (Walker and 
Meyers 2004).

Transformation strategy is the capacity of the system to cross thresholds into new development trajectories. It is the capacity of the system to literally transform itself into a different kind of system. Transformation strategy becomes very important when a system is in a stability regime that is considered undesirable, and it is either impossible, or getting progressively harder and harder, to engineer a 'flip' to the original or some other regime of that same system. The system will have a different identity. (Folke, Carpenter et al. 2010).

\subsection{Problem Definition and Research Objective}

The problem that this work addresses, is how business enterprises can formulate a resilience strategy and develop and deploy a resilience roadmap when faced with strategic disruptions, in a way that ensures survivability of these business enterprises.

Traditional strategic management approaches are not enough to address this problem. This is clear when we look at the difference of results between Fujifilm and Kodak. Both enterprises faced the same disruption, the digital photography that impacted their core film businesses. Both enterprises were successful in applying traditional strategic management approaches for decades. However, in facing the storm of the digital disruption, FujiFilm responded differently than Kodak. After the storm, Fujifilm became a much more successful company with diversified business, ranging from optical devices to radiopharmaceuticals, while Kodak filed for bankruptcy in 2012 (Komori 2015). Fujifilm was a resilient enterprise while Kodak was not. This points clearly to a gap in having a clear resilience approach that stitches together strategies and actions in a way that enables the business enterprise to survive the storm successfully.

The goal and contribution of this work is to propose a resilience-based framework (figure 2) for addressing strategic disruptions that can be used independently of other domains such as strategic management or Enterprise Risk Management, but also in collaboration with these domains. The proposed resilience-based framework is overlaid over the enterprise architecture framework. The reason for this is that, when enterprises are engaged in strategic transformation in response to strategic disruptions, they make use of enterprise architectures to direct the development and change of the enterprise as a whole since enterprise architecture is concerned with the overall steering of the direction in which the enterprise aims to transform itself (Lankhorst 2009). The enterprise architecture should provide an elaboration of the enterprise's vision such that it enables the steering and coordination of all the actions involved in the transformation. In that sense the enterprise architecture is a bridge from vision to implementation (Fehskens 2008). 


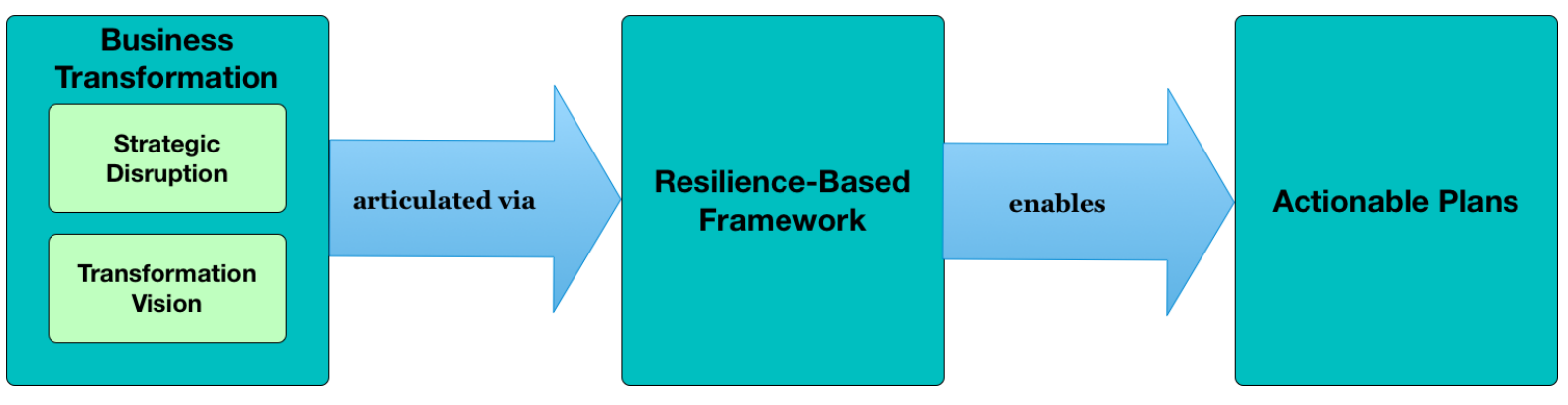

Figure 2. Resilience Based Framework

\section{Methodology}

For this work, the design science research methodology (DSRM) suggested by (Peffers, Tuunanen et al. 2007) was adopted. This process proposes six consecutive steps where the output of each is treated as input in the next one and with some iterative activity. The first step is the problem identification and motivation, where the specific research problem is defined, and the value of the solution is justified. The second step is the definition of the objectives for a solution, during which the objectives of the solution are deducted from the problem definition in the previous step and from what is feasible. During the third activity of design and development the actual artefact is created. In the fourth activity, the use of the artefact is demonstrated. Evaluation of the artefact is the fifth activity with observation and measurement of how well the designed artefact supports a solution to the problem. In the final activity, communication takes place about the problem and its importance, and about the artefact and its quality characteristics.

\subsection{Synthesizing the Integrated Resilience Framework}

Only resilient business enterprises like Fujifilm (Komori 2015) and IBM (Garr and Redux 2000) are able to survive game-changing strategic disruptions and come back as more successful enterprises than they were before the disruptions. Resilient business enterprises apply resilience concepts to build the components and capabilities that enable them to survive and transform themselves at the times when that need to face strategic disruptions. Management of resilient business enterprises use the resilience strategies of mitigation, adaptation, and transformation and execute them at the right times and in the right combinations for their enterprises in facing the strategic disruptions (Folke, Carpenter et al. 2002).

Concepts applied by successful resilient enterprises like Fujifilm are captured and used to develop an integrated resilience-based framework. Business enterprises can use the proposed integrated resilience-based framework to prepare themselves and guide their actions to survive strategic disruptions. The foundation of the framework is the resilience concepts and resilience strategies. The framework is synthesized from a set of tools, strategies, frameworks, and information that are derived from nature of the behaviours of business enterprises facing disruptions, the stages that these business enterprises go through facing these disruptions, and the characteristics of the ones that survive these disruptions. 


\subsection{Framework Requirements}

In order for the resilience-based framework to be an affective framework that can guide business enterprises to survive game-changing strategic requirements, it must fulfil the following requirements:

Table 1. Framework Requirements

\begin{tabular}{|c|c|}
\hline $\begin{array}{l}\text { Framework } \\
\text { Requirement }\end{array}$ & Des \\
\hline $\begin{array}{l}\text { Monitor and } \\
\text { interpret shifts } \\
\text { in the } \\
\text { environment }\end{array}$ & $\begin{array}{l}\text { The framework must allow monitoring changes in the environment and interpreting these } \\
\text { changes into possible trajectories of the future. By environment here we mean, the } \\
\text { pattern of all the external conditions and influences that affect its life and development of } \\
\text { an enterprise, and they include the dimensions: social, technological, environmental, } \\
\text { economic, and political. The importance of this requirement is that, a business enterprise } \\
\text { cannot be resilient against all possible types of disruptions since this is economically } \\
\text { impossible (May, Levin et al. 2008). }\end{array}$ \\
\hline $\begin{array}{l}\text { Apply the } \\
\text { operating } \\
\text { efficiency }\end{array}$ & $\begin{array}{l}\text { The framework must allow applying the scenario of moving parts of the enterprise's } \\
\text { operating model to their efficiency frontier. By operating model, we mean all the } \\
\text { components that depict how the business operates on a daily basis (Winter and Fischer } \\
\text { 2006). Changing the operating model in this way has two outcomes; the first is the reverse } \\
\text { or slowdown of the negative impact of the strategic disruption, and the second is } \\
\text { accumulating more resources that will be needed if a subsequent transformation phase is } \\
\text { to take place. }\end{array}$ \\
\hline $\begin{array}{l}\text { Apply the } \\
\text { adaption }\end{array}$ & $\begin{array}{l}\text { The framework must allow applying the adaption scenario (Walker and Meyers 2004) to } \\
\text { recover from the impact of a strategic disruption. Business enterprises recover from } \\
\text { impact of strategic disruption through either finding other markets for their products and } \\
\text { services or through scaling down to match the impact of the strategic disruption. The goal } \\
\text { of the adaptation strategy is to survive the impact, minimize cost, liquidate the released } \\
\text { resources and add them to the resource base needed during the transformation strategy } \\
\text { phase. }\end{array}$ \\
\hline
\end{tabular}




\begin{tabular}{|c|c|}
\hline $\begin{array}{l}\text { Apply the } \\
\text { transformation }\end{array}$ & $\begin{array}{l}\text { The framework must allow applying the transformation scenario to deliberately redesign } \\
\text { the business enterprise. The resilient business enterprise applies the resilience } \\
\text { transformation scenario through changing the business model of the business enterprise. } \\
\text { The transformation scenario shakes the very foundation of the enterprise, transform it } \\
\text { into a different kind of an enterprise, and change its identity (Folke, Carpenter et al. 2010). }\end{array}$ \\
\hline $\begin{array}{l}\text { Articulate the } \\
\text { core } \\
\text { capabilities of } \\
\text { the business } \\
\text { enterprise }\end{array}$ & $\begin{array}{l}\text { The framework must articulate the core capabilities of the business enterprise that will be } \\
\text { the base for transformation based on diversifying their uses and applications. The reason } \\
\text { for this requirement is that, resilient business enterprises build in-house core capabilities } \\
\text { that are valuable, rare, inimitable and non-substitutable. Around these core capabilities, } \\
\text { business models of these enterprises can be changed (Barney 1991). }\end{array}$ \\
\hline $\begin{array}{l}\text { Organize } \\
\text { enterprise } \\
\text { concepts into } \\
\text { layers with } \\
\text { different rate } \\
\text { of change }\end{array}$ & $\begin{array}{l}\text { The reason for this requirement is that, this kind of organization make the enterprise more } \\
\text { adaptive and the transformation process smoother. We learnt this from the concept of } \\
\text { systems architectonics that is used to describe how to design buildings that can learn, by } \\
\text { proposing several constructional layers that change at different rates. The more these } \\
\text { layers can evolve without requiring changes to other layers, the more adaptable the } \\
\text { building is (Galal-Edeen 2008). }\end{array}$ \\
\hline $\begin{array}{l}\text { Develop IT } \\
\text { architecture } \\
\text { that is } \\
\text { business } \\
\text { driven }\end{array}$ & $\begin{array}{l}\text { The framework must allow developing the IT architecture based on the required } \\
\text { transformation of the business. This requirement can be realized through a mapping } \\
\text { process from the business concepts to IT concepts. }\end{array}$ \\
\hline
\end{tabular}

\section{Integrated Enterprise Resilience Architecture Framework}

The proposed resilience-based framework is overlaid over the enterprise architecture framework since enterprise architecture is the tool that is concerned with the whole enterprise; business, information, and technology (Lankhorst, 2009). Enterprise architecture is a tool that can translate a business vision into effective enterprise change by creating, communicating and improving the key requirements, principles and models that describe the enterprise's future state and enable its evolution (Lapkin, Allega et al., 2008). The defining characteristic of enterprise architecture is that it crosses internal organizational boundaries and provides 
coordinated views of the entire enterprise, acting as a single source of reference and thus efficiently supporting management planning and decision making (Bernard, 2012).

For this work, we use TOGAF framework (Josey, 2011) and business architecture framework (GUILD, 2014), as the foundation for the integrated enterprise resilience architecture framework. TOGAF framework is composed of many different parts, but the largest and most well-known is the Architecture Development Method (ADM). The architectural domains are described in terms of phases of the ADM, starting with Business, then Information Systems (a combination of Data and Application), and Technology. And while TOGAF does describe some artefacts, there is significant flexibility in what artefacts should be produced and as to the degree of formality present (Josey, 2011). The business architecture framework represents holistic, multidimensional business views of capabilities, end-to-end value delivery, information, and organizational structure; and the relationships among these business views and strategies, products, policies, initiatives, and stakeholders (GUILD, 2014).

The reason for choosing this combination is that, the mix of the two frameworks address the requirements of the framework that we present above. Another reason is that, the two frameworks can be combined and integrated together perfectly. TOGAF is a generic and customizable framework that can be combined and integrated with other frameworks for processes and/or contents (Josey, 2011). TOGAF has a business architecture development phase (Josey 2011) that can be integrated with business views created by the business architecture framework (GUILD, 2014).

Three main usage scenarios for the enterprise architecture within the context of the resilience analysis: changing the operating model of the enterprise, changing the competitive strategies of the enterprise, and changing the business model of the enterprise. The three scenarios correspond to the three resilience strategies of mitigation, adaptation, and transformation. The mitigation strategy in this context has the mission of moving the operating model to the efficiency frontier. The adaption strategy in this context applies several competitive strategies to recover from the impacts of the strategic disruptions. The transformation strategy in this context changes the business model of the business which transforms the enterprise into a new identity.

\subsection{Enterprise Resilience Architecture Development Method}

Based on the combination between TOGAF ADM, the business architecture framework and the framework requirements, we have developed a method that can guide business enterprises in addressing strategic disruptions as per figure 3 . The details of the method are shown in figure 4. 


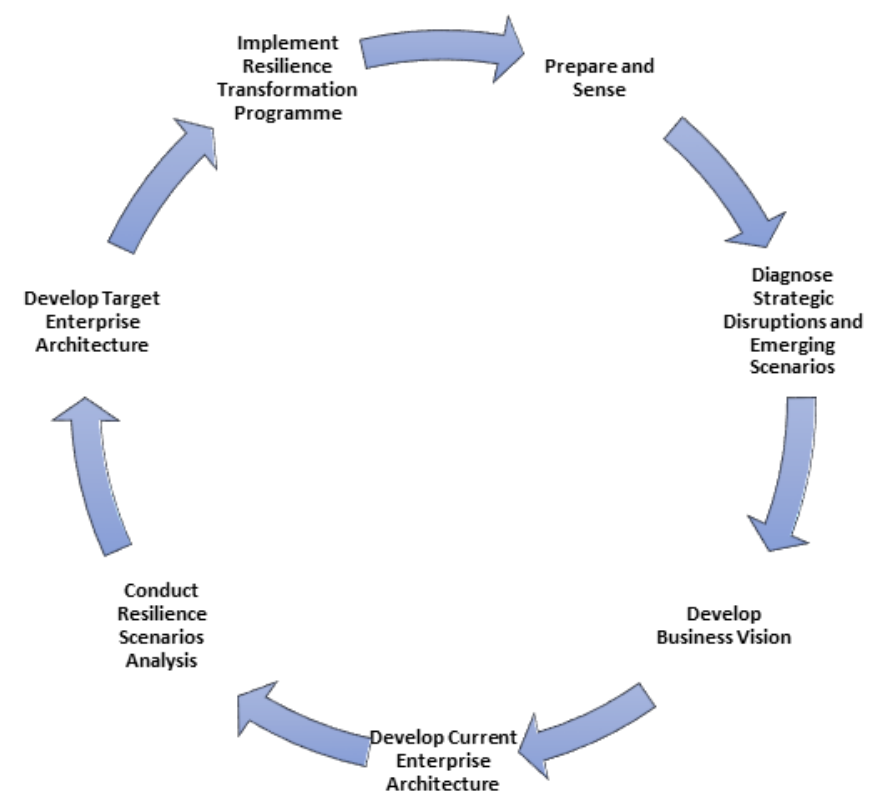

Figure 3. Enterprise Resilience Architecture Development Method
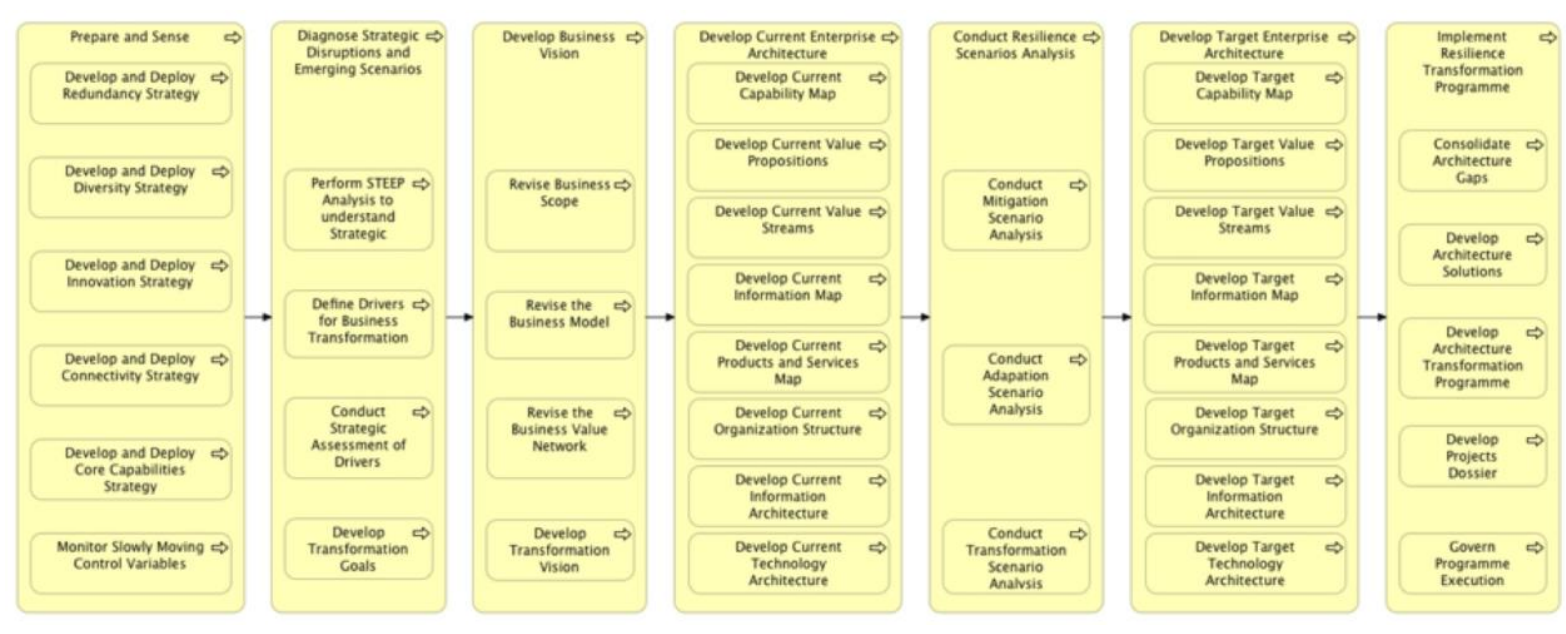

Figure 4. Detailed Enterprise Resilience Architecture Development Method

\subsubsection{Prepare and Sense}

In this phase, the business enterprise prepares itself to deal with strategic disruptions through instilling the resilience design characteristics throughout the organization. These characteristics enable the enterprise to apply the required resilience strategies to survive and persist when facing strategic disruptions (Reeves, Levin et al. 2016). The business enterprise develops and deploys strategies to instil the necessary redundancy, diversity, connectivity, innovation, and core capabilities throughout the organization.

Also, in this phase, the business enterprise monitors the control variables that if crossed their 
thresholds, can shift the business enterprise into undesirable regime. Approaching the thresholds of one or more control variables indicates the possibility of emergence of a strategic disruption and kicks off the next phase of diagnosing this situation.

\subsubsection{Diagnose Strategic Disruptions}

In this phase, the business enterprise conducts environment analysis to understand the forces that cause the strategic disruptions. Strategic disruptions create drivers for the business enterprise to transform itself. The business enterprise needs to assess these drivers, a process that results in creating a set of transformation goals.

\subsubsection{Develop Business Vision}

In this phase, the business enterprise revises its business scope, business model, and value network in light of the transformation goals that have been identified in the previous phase. Based on these revisions, the business enterprise formulates a transformation vision that will guide all the architecture effort that will follow.

\subsubsection{Develop Current Enterprise Architecture}

In this phase the business enterprise captures the current enterprise architecture in terms of capabilities, value propositions, value streams, organization structure, information, products \& services, application, data, and technology. The business enterprise will then use these concepts to create business blueprint views of the current state of the business.

\subsubsection{Conduct Resilience Scenario Analysis}

The blueprint views created in the previous phase, will be analysed in light of the strategic disruption dimensions and the transformation vision created in the previous phase. These analyses will typically be part of the resilience scenarios: mitigation scenario, adaptation scenario, and transformation scenario; mentioned in the framework requirements. For example, as part of the mitigation scenario, the business enterprise may ask: for a specific customer segment, what are value streams that if streamlined and optimized will maximize the value delivered to this segment? Then, the business enterprise can determine which capabilities are enabling these value streams and the information systems that support these capabilities.

\subsubsection{Develop Target Enterprise Architecture}

Based on the analyses done in the previous phase, the business enterprise develops a target enterprise architecture in terms of target capabilities, value propositions, value streams, organization structure, information, and products \& services, applications, data, and technology. The business enterprise conducts an architecture gap analysis to define the enterprise gaps between the current enterprise architecture and the target enterprise architecture.

\subsubsection{Implement Resilience Transformation Programme}

In this phase, the business enterprise consolidates the enterprise architecture gaps identified in 
the previous phase, develops a consolidated enterprise architecture solution that addresses these gaps, creates a transformation programme and roadmap that crosses over the business lines, departments, products \& services, customer segments, and information technology. A transformation map created this way, ensures integrated execution, effective investment, non-duplicated, and non-fragmented initiatives. In this phase, the business enterprise ensures conformance of the programme projects execution with the target enterprise architecture.

\subsection{Enterprise Resilience Architecture Meta-Model}

At the core of the integrated enterprise resilience architecture framework is the framework's Meta-Model. Contents of the resulted architectures are created based on this framework's Meta-Model. These enterprise architecture contents form what is called, the enterprise architecture knowledgebase, which provides the foundational perspective for formalizing the definition, relationships, and management of the enterprise architecture artefacts. The knowledgebase is the centrepiece of the enterprise resilience architecture framework. The foundation of the knowledgebase is the enterprise architecture Meta-Model. The Meta-Model identifies the artefacts and relationships that serve as the foundation for storing and automating an enterprise architecture practice. The enterprise architecture Meta-Model is based upon a set of core concept terms or "domain categories" and relationships among those domain categories (Josey 2011).

The following figure (figure 5) shows the concepts of the Meta-Model that we use for creating the knowledgebase of the integrated enterprise resilience architecture framework:

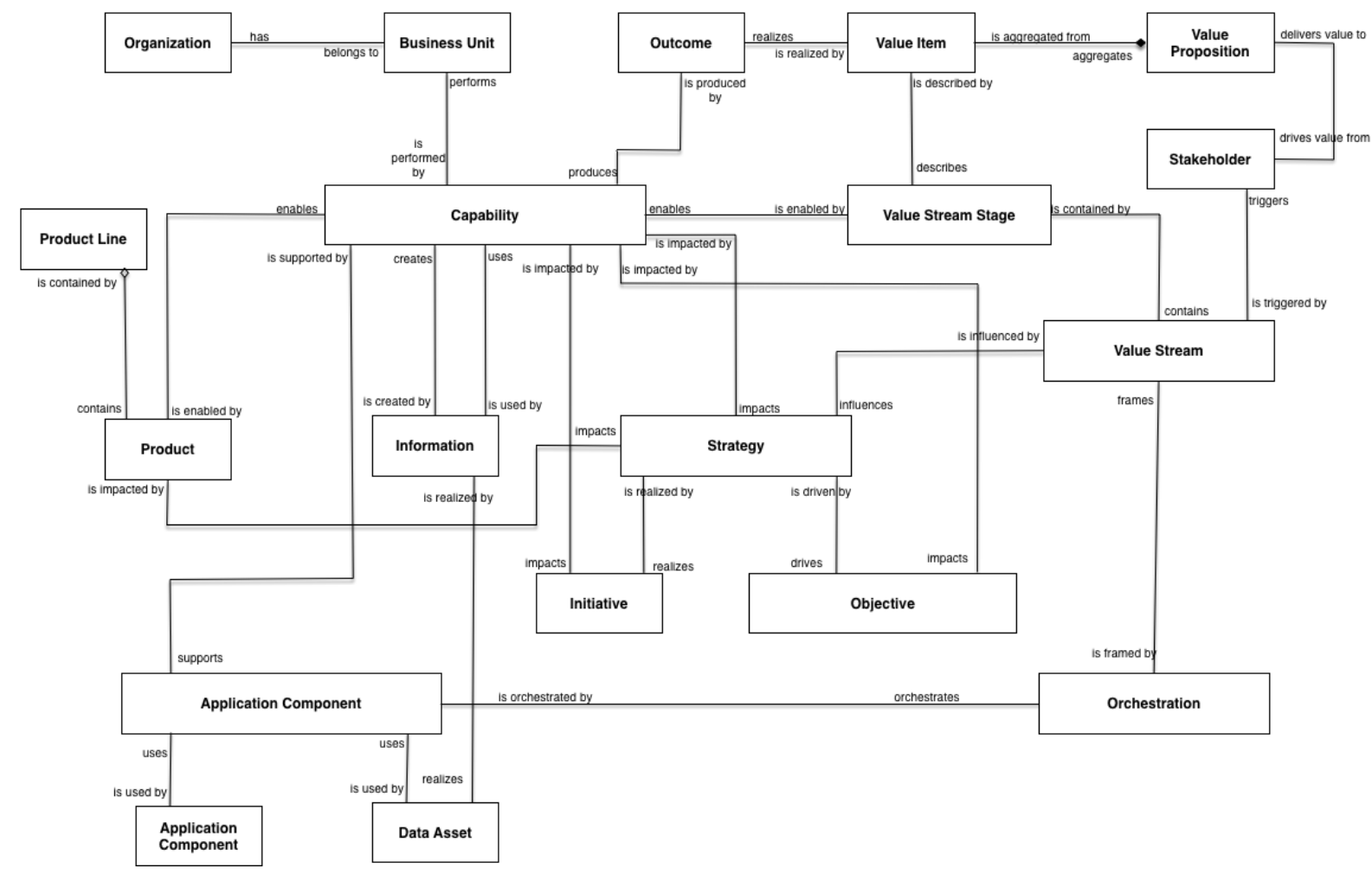

Figure 5: Enterprise Resilience Architecture Meta-Model 


\begin{tabular}{|c|c|}
\hline $\begin{array}{l}\text { Enterprise Resilience } \\
\text { Architecture Concept }\end{array}$ & Enterprise Resilience Architecture Concept Definition \\
\hline Capability Concept & $\begin{array}{l}\text { Capabilities describe what the business does and what it will need to do differently } \\
\text { in response to strategic challenges and opportunities. They combine resources, } \\
\text { competences, information, processes and their environments to deliver consistent } \\
\text { outcome (Burton 2010). }\end{array}$ \\
\hline $\begin{array}{l}\text { Organization and } \\
\text { Business Unit } \\
\text { Concept }\end{array}$ & $\begin{array}{l}\text { The business unit is the main concept used to establish organization maps. It is } \\
\text { defined as follows: "A logical element or segment of a company (such as } \\
\text { accounting, production, marketing) representing a specific business function, and a } \\
\text { definite place on the organization chart, under the domain of a manager. Also, } \\
\text { called department, division, or a functional area" (Ulrich and Rosen 2014). }\end{array}$ \\
\hline Stakeholder Concept & $\begin{array}{l}\text { Stakeholder is defined as an internal or external individual or organization with a } \\
\text { vested interest in achieving value through a particular outcome (Ulrich and Rosen } \\
\text { 2014). }\end{array}$ \\
\hline $\begin{array}{l}\text { Value and Value } \\
\text { Proposition Concept }\end{array}$ & $\begin{array}{l}\text { Value can be defined as the benefit that is derived by an organization's stakeholder } \\
\text { while interacting with that organization. Value is fundamental to everything that an } \\
\text { organization does. In fact, the only reason an organization exists is that it provides } \\
\text { value to one or more stakeholders (Brandenburger and Stuart 1996). A value } \\
\text { proposition is defined as: "An innovation, service, or feature intended to make a } \\
\text { company, product, or service attractive to customers or related stakeholders" } \\
\text { (Frow and Payne 2011). }\end{array}$ \\
\hline Information Concept & $\begin{array}{l}\text { Accurate, timely, relevant information is crucial to good decision-making, including } \\
\text { strategic decisions (Choo 1996). Information and knowledge are key assets in the } \\
\text { current knowledge worker-driven economy. It has been consistently shown that } \\
\text { information is essential for innovation in a culture that encourages and rewards } \\
\text { intelligent risk taking. Information facilitates the assessment of both upside and }\end{array}$ \\
\hline
\end{tabular}




\begin{tabular}{|c|c|}
\hline & downside risk associated with a course of action (De Jong, Marston et al. 2013). \\
\hline Outcome & $\begin{array}{l}\text { An outcome represents an end result that has been achieved. Outcomes are } \\
\text { high-level, business-oriented results produced by capabilities of an organization, } \\
\text { and by inference by the core elements of its architecture that realize these } \\
\text { capabilities. Outcomes are tangible, possibly quantitative, and time-related, and } \\
\text { can be associated with assessments. An outcome may have a different value for } \\
\text { different stakeholders (Josey, Lankhorst et al. 2016). }\end{array}$ \\
\hline Product Concept & $\begin{array}{l}\text { Product can be defined as a good, idea, method, information, object, or service that } \\
\text { is the end result of a process and serves as a need or want satisfier. It is usually a } \\
\text { bundle of tangible and intangible attributes (benefits, features, functions, uses) } \\
\text { that a seller offers to a buyer for purchase. Products can be goods or services, and } \\
\text { are distinguished by tangibility: goods are tangible, and services are intangible. } \\
\text { Product can also be referred to as the overall experience provided by the } \\
\text { combination of goods and services to satisfy the customer's needs (Geracie and } \\
\text { Eppinger 2013). }\end{array}$ \\
\hline Strategy Concept & $\begin{array}{l}\text { A strategy is an approach or plan for configuring some capabilities and resources of } \\
\text { the enterprise, undertaken to achieve a goal. It is the pattern or plan that } \\
\text { integrates an organization's major goals, policies and action sequences into a } \\
\text { cohesive whole (Quinn 1980). }\end{array}$ \\
\hline Initiative Concept & $\begin{array}{l}\text { Application is the common terminology used to characterize a collection of } \\
\text { software assets that automates and enables a bounded set of capabilities and is } \\
\text { identifiable by name and other characteristics. These assets must be assessed for } \\
\text { investment purposes just like any other asset. An application may decompose into } \\
\text { smaller chunks. These chunks have historically been called subsystems, but other } \\
\text { terms may also apply (Kellerman and Löfgren 2008). }\end{array}$ \\
\hline Data Concept & $\begin{array}{l}\text { Data is often defined "as being discrete, objective facts or observations, which are } \\
\text { unorganized and unprocessed and therefore have no meaning or value because of } \\
\text { lack of context and interpretation". Information may be built on top of data but } \\
\text { may also only exist in the mind of a person or be conveyed in speech or ephemeral }\end{array}$ \\
\hline
\end{tabular}




\begin{tabular}{|l|l|}
\hline $\begin{array}{l}\text { Orchestration } \\
\text { Concept }\end{array}$ & $\begin{array}{l}\text { documents; information is the combination of data and a context for interpreting } \\
\text { that data (Ulrich and Rosen 2014). } \\
\text { stream / capability cross-mappings provide insights into service and application } \\
\text { orchestration. When a business needs to improve or even add capabilities based on } \\
\text { any number of business scenarios, capabilities and value streams provide architects } \\
\text { with a framework for business service and service orchestration requirements } \\
\text { (Ulrich and Rosen 2014). }\end{array}$ \\
\hline
\end{tabular}

Table 2: Meta-Model Concepts

\section{Demonstrating the Method - ArchiSurance Case Study}

ArchiSurance is a company that was created after the merger of three other previously independent insurance companies to take advantage of the numerous synergies between them in order to control costs, maintain customer satisfaction, invest in new technology and take advantage of emerging markets with high growth potential. They realized that only a larger, combined company could achieve these goals when lower-cost competitors started entering their markets and at the same time new opportunities in high-growth regions emerged; thus, they decided to join forces (Jonkers, Band et al. 2012).

The three original organizations were 'Home \& Away', which provided home and travel insurance to its clients; 'PRO-FIT', which provided auto insurance; and 'Legally Yours', which was specializing in legal expense insurance. Although the three pre-merger companies were selling different types of insurance, they had similar business models; they all sold direct to consumers and small businesses through the Web, email, telephone and postal mail channels, without using an intermediary channel. The created company, operating as ArchiSurance, is now providing all the aforementioned services of the three pre-merger companies (as shown below in Figure 6). Like its three predecessors, ArchiSurance sells directly to customers via print, Web, and direct marketing and intends to frequently adjust its offerings in response to changing market conditions (Jonkers, Band et al. 2012). 


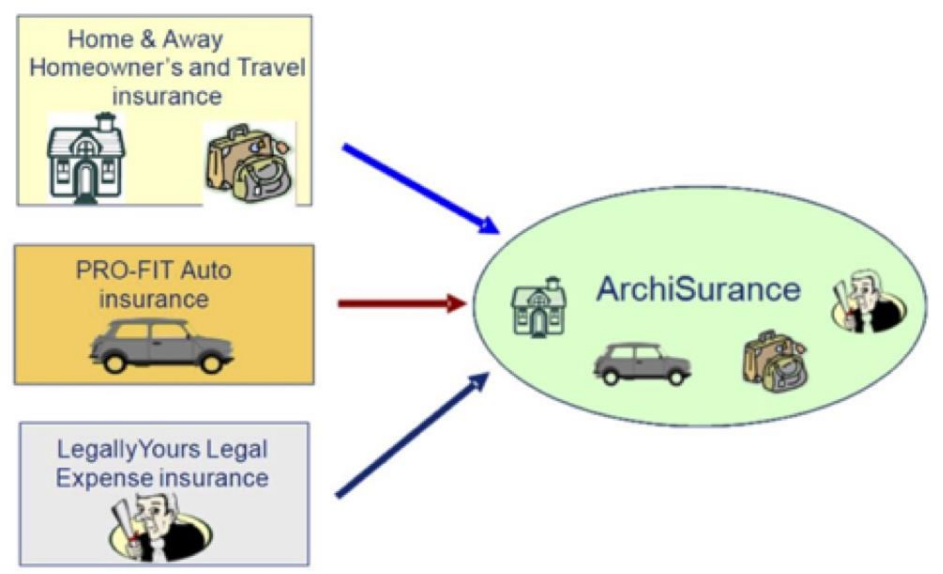

Figure 6. ArchiSurance: The Result of a Merger of Three Insurance Companies

After the merger, ArchiSurance set up a shared front-office as a multi-channel contact centre for sales and customer service at the pre-merger headquarters of Home \& Away. There are still three separate back-offices that handle the insurance products of the three original companies. A Shared Service Centre (SSC) has been established for document processing at the pre-merger headquarters of PROFIT (Jonkers, Band et al. 2012). The organization structure of the merged ArchSurance company is shown in figure 7.

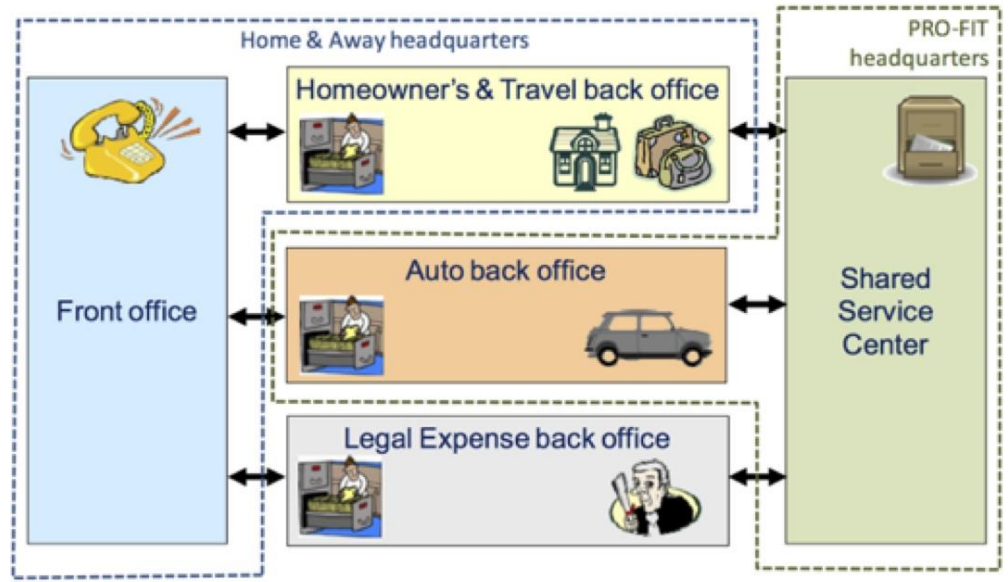

Figure 7. Global Organizational Structure of ArchiSurance

\subsection{Diagnose Strategic Disruptions}

In spite the successful take-off of ArchiSurance, the enterprise faces a wave of decreasing profitability and rapid increasing migration of customers to competitors. The company is struggling to cope with the huge social changes in consumer attitudes and behaviours. The traditional insurance model adapted by ArchiSurance is being challenged by the adoption of innovative usage-based business models and telematics by the competition, as well as by 


\section{Macrothink}

Enterprise Risk Management

ISSN 1937-7916

2018, Vol. 4, No. 1

increased capital requirements and regulatory oversight across the world. ArchiSurance is not the only insurance enterprise that faces this wave.

The first thing the enterprise decided to do is to understand the driving forces of the strategic shifts that shape the sector's landscape and cause the disruption wave. ArchiSurance conducted a STEEP (Social, Technological, Environmental, Economic, and Political) analysis to understand these driving forces.

\begin{tabular}{|c|c|}
\hline Aspect & Assessment \\
\hline Social & $\begin{array}{l}\text { - The ongoing social trend is causing the insurance to be transformed from } \\
\text { being 'sold or pushed to customers' to being 'bought' by customers. This } \\
\text { requires insurance companies including agents, advisors and carriers to } \\
\text { re-examine their roles in the insurance value chain (Yoder, Rao et al. 2012). } \\
\text { - The rapid adoption and fast evolution of social networks continue to } \\
\text { empower both consumers and businesses and create what is called virtual } \\
\text { communities (Yoder, Rao et al. 2012). }\end{array}$ \\
\hline Technology & $\begin{array}{l}\text { - The growth in smartphones and tablets, the growth in cloud computing, the } \\
\text { explosion of computing power and storage and the growth in active sensors } \\
\text { and devices connected to the internet; create big data that is accumulated } \\
\text { and analysed can provide insurance companies competitive advantage in } \\
\text { pricing, underwriting and loss control (Yoder, Rao et al. 2012). } \\
\text { Digital technologies including social, mobile, analytics, IOT, Al, Machine } \\
\text { Learning and blockchain present opportunities to offer new, compelling value } \\
\text { propositions that combine existing competencies with the capabilities of new } \\
\text { technologies (Yoder, Rao et al. 2012). }\end{array}$ \\
\hline Environment & $\begin{array}{l}\text { - The severity and frequency of catastrophic events, both natural and } \\
\text { man-made, have been increasing over the years (Yoder, Rao et al. 2012). } \\
\text { With continued fossil fuel use, pollution will remain a significant health issue, } \\
\text { threatening the well-being of populations in developed and developing } \\
\text { countries (Yoder, Rao et al. 2012). } \\
\text { Life and health insurers will need to closely monitor trends in atmospheric }\end{array}$ \\
\hline
\end{tabular}




\begin{tabular}{|c|c|}
\hline & $\begin{array}{l}\text { pollution in order to accurately assess risk in different regions (Yoder, Rao et } \\
\text { al. 2012). }\end{array}$ \\
\hline Economic & $\begin{array}{l}\text { - The world economy is shifting from a world dominated by developed markets } \\
\text { to a world in which the majority of growth is in emerging markets (Yoder, Rao } \\
\text { et al. 2012). } \\
\text { - In the developed world, the old outnumber the young. In emerging markets } \\
\text { (except China) the working age population will continue to outnumber the } \\
\text { dependent population, and thereby result in more productive growth (Yoder, } \\
\text { Rao et al. 2012). } \\
\text { The rise of the middle class in emerging markets is fuelling increased } \\
\text { consumption, which is leading to impressive small business growth (Yoder, } \\
\text { Rao et al. 2012). } \\
\text { In developing countries, government infrastructure investment, population } \\
\text { growth, new businesses and wealth creation are driving growth in } \\
\text { construction, land development, energy and transportation sectors, all of } \\
\text { which are creating a greater need for insurance (Yoder, Rao et al. 2012). }\end{array}$ \\
\hline Political & $\begin{array}{l}\text { - Consumers lacking faith in the solvency of social security programmes will } \\
\text { begin to focus on providing their own savings for retirement, away from } \\
\text { government programmes (Yoder, Rao et al. 2012). } \\
\text { - This will create new opportunities for life and annuity insurers (Yoder, Rao et } \\
\text { al. 2012). } \\
\text { Over the past } 3 \text { decades, there has been an increase in terrorist attacks } \\
\text { around the world. These terrorist attacks often impact multiple product lines, } \\
\text { which are often modelled independently. Detailed modelling is required to } \\
\text { understand the capacity requirements for terrorism coverage (Yoder, Rao et } \\
\text { al. 2012). }\end{array}$ \\
\hline
\end{tabular}

Table 3. STEEP Analysis of Insurance Industry

Based on the STEEP analysis, ArchiSurance diagnosed the situation as a strategic disruption 
caused by the interaction of STEEP forces shifts.
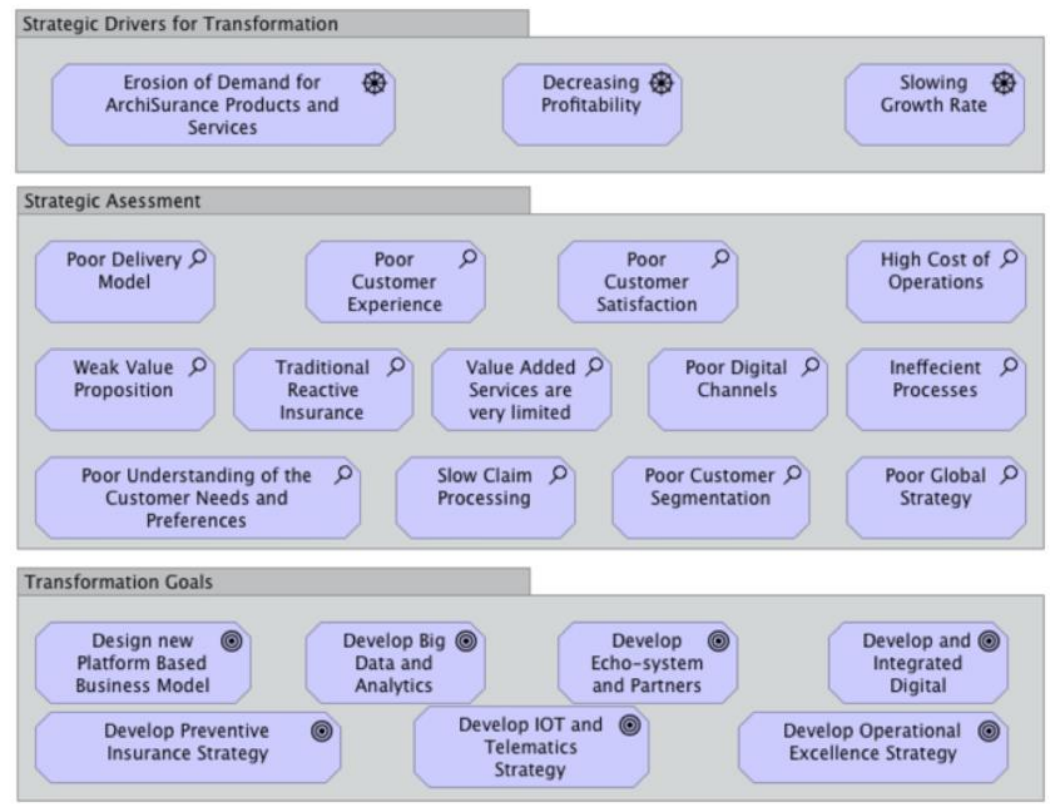

Figure 8. Strategic Disruption Diagnosis

\subsection{Develop Business Vision}

ArchiSurance created a vision (Figure 9) for a new business model that is based on a customer engagement and preventive insurance strategies. The target business model is enabled by a digital core that transforms the customer interaction approach and delivers personalized value propositions based on the preventive insurance concept. 


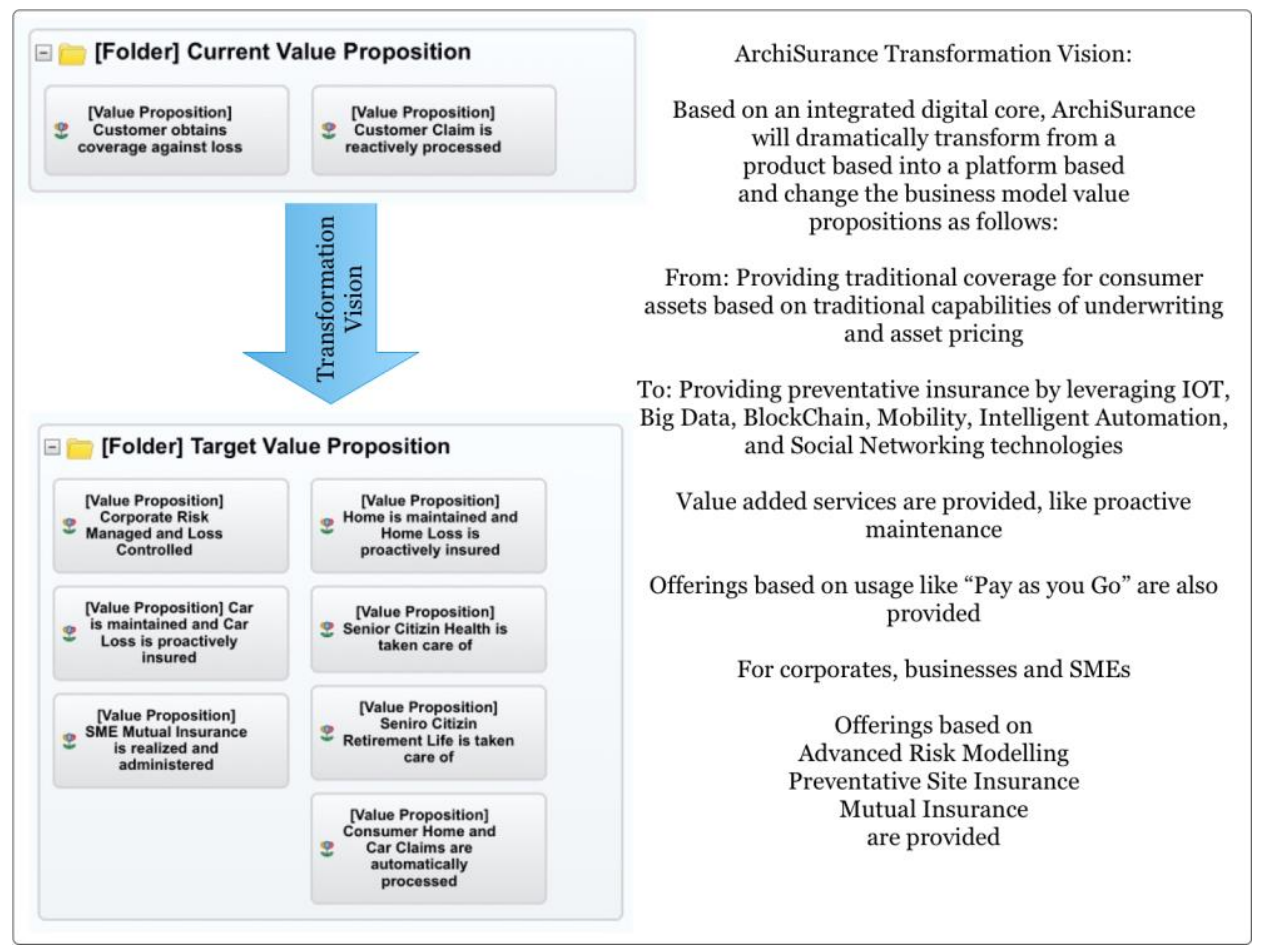

Figure 9: Transformation Vision

The vision depends on creating an integrated digital core as per figure 10:

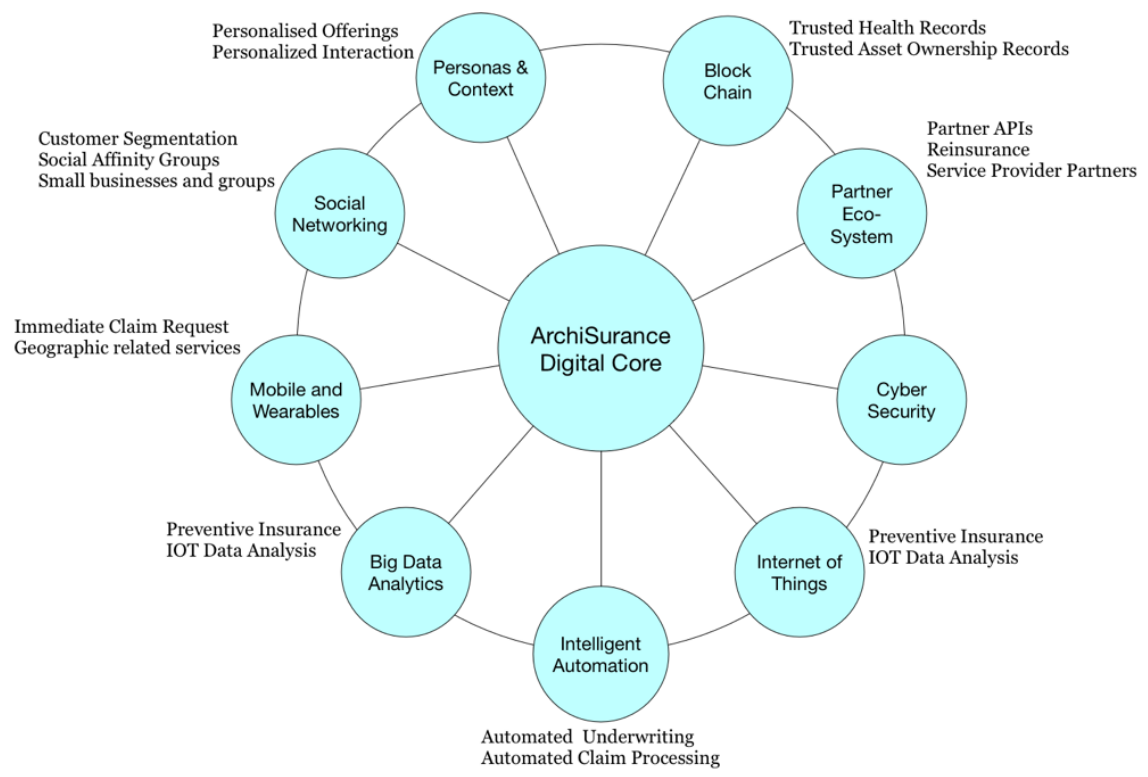

Figure 10. Envisioned Integrated Digital Core

ArchiSurance created a new platform based business model as shown in figure 11: 


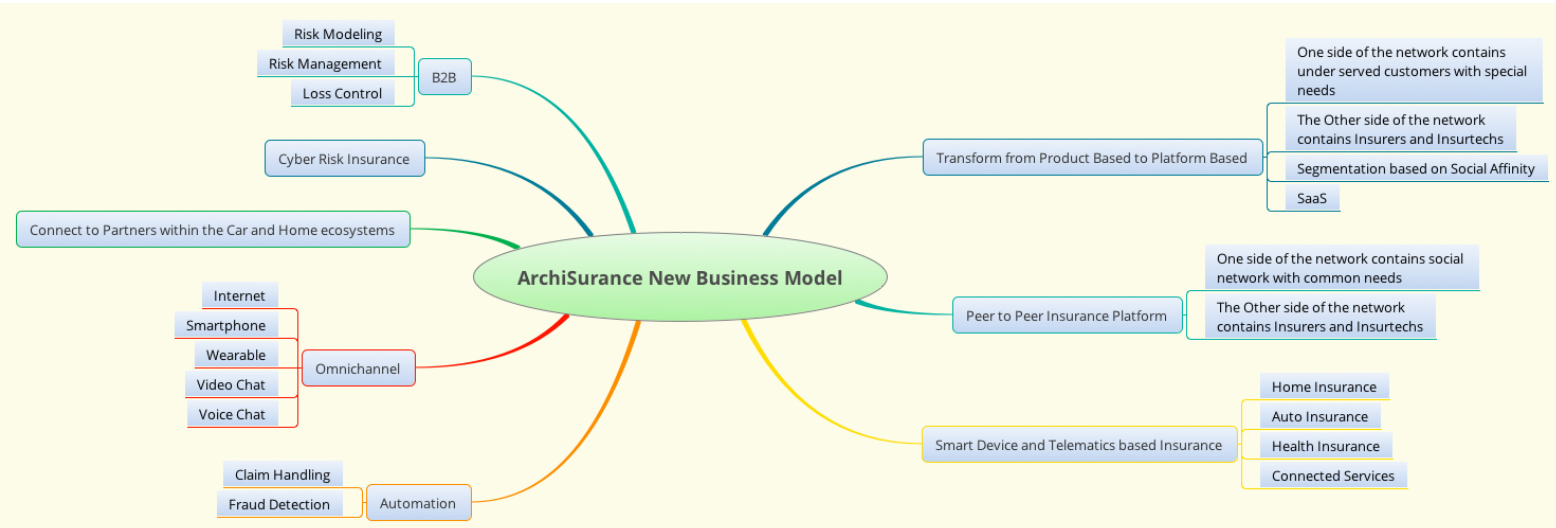

Figure 11. ArchiSurance New Business Model

\subsection{Develop Current Enterprise Architecture}

ArchiSurance mapped the current core capabilities as shown in figure 12:

\section{ArchiSurance Core Capabilities Diagram}

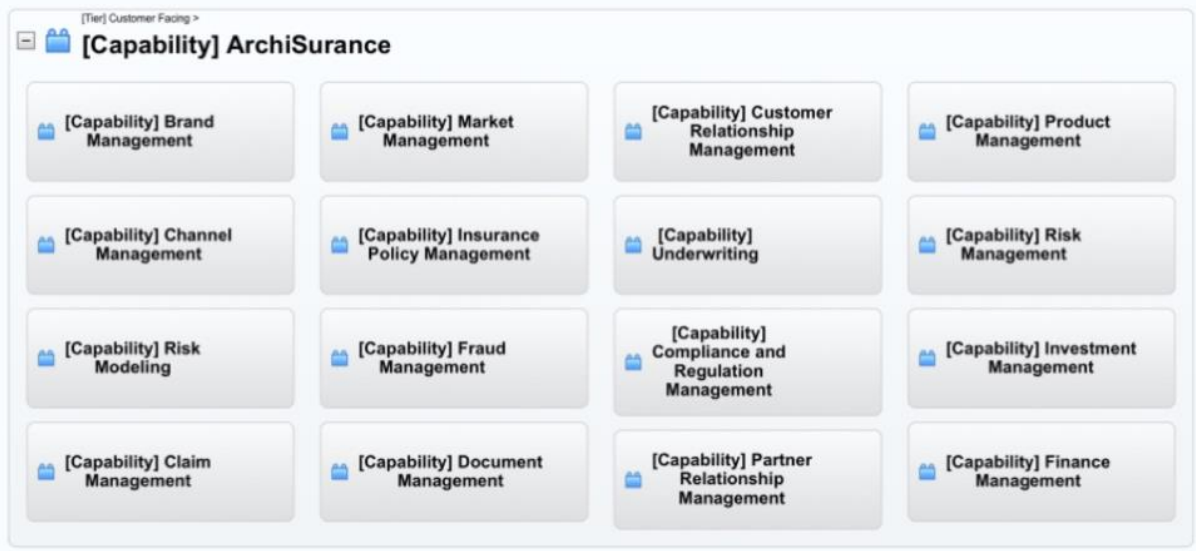

Figure 12. ArchiSurance Current Core Capabilities

ArchiSurance mapped the current application landscape as shown in figure 13: 


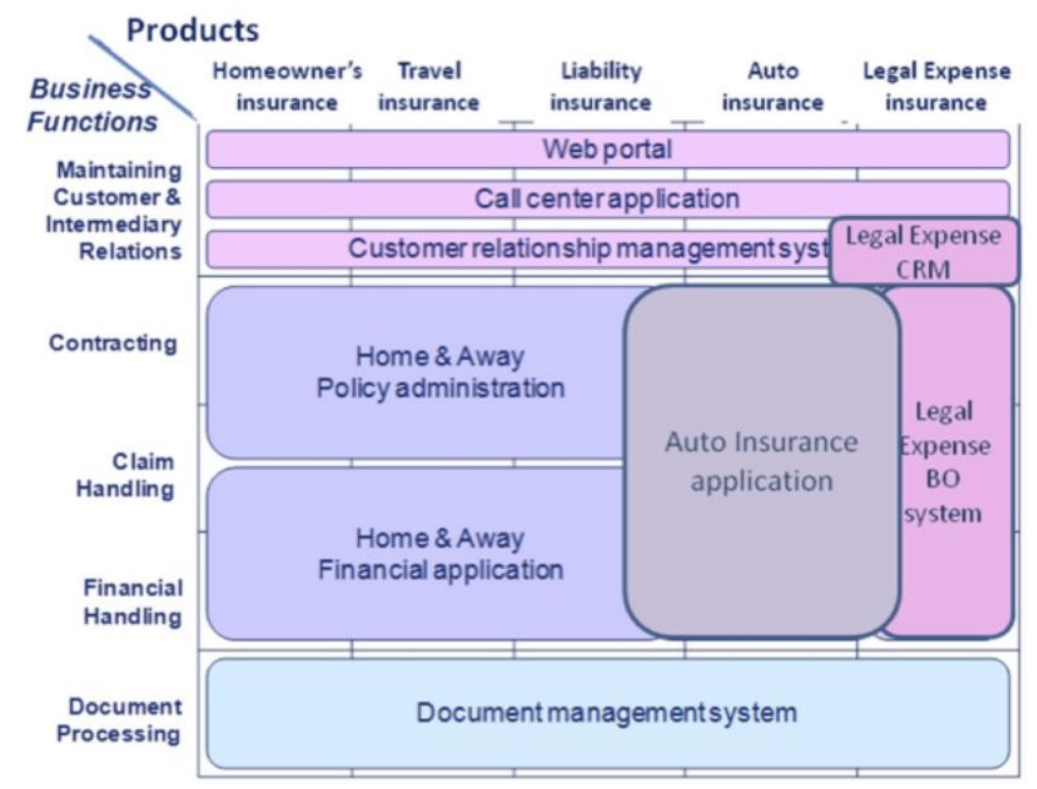

Figure 13. ArchiSurance Current Application Landscape

\subsection{Conduct Resilience Scenario Analysis}

ArchiSurance conducted resilience scenarios as follows:

Table 4. Resilience Scenarios

\begin{tabular}{|c|c|}
\hline Mitigation Scenario & $\begin{array}{l}\text { ArchiSurance decided to move to the operational frontier and enhancing the } \\
\text { customer experience through the following initiatives: } \\
\text { 1- Automate the Underwriting Process } \\
\text { 2- Automate Real-time Fraud Detection } \\
\text { 3- Enable customers to submit claims through smart phones } \\
\text { These initiatives enable ArchiSurance to grow the current markets and boost } \\
\text { current customer loyalty. This way it can sustain the current business model, } \\
\text { delay the impact of the disruptive forces, and provide a strong base for the }\end{array}$ \\
\hline
\end{tabular}




\begin{tabular}{|l|l|}
\hline Adaptation Scenario & $\begin{array}{l}\text { ArchiSurance started a restructuring initiative to reduce cost and match the } \\
\text { decline trend. Saved resources are used to fuel the transformation scenario. }\end{array}$ \\
\hline Transformation Scenario & $\begin{array}{l}\text { ArchiSurance launched a Transformation Programme to transform the business } \\
\text { model from a product-based insurance business model into a platform-based } \\
\text { insurance business model. ArchiSurance created several initiatives to build a } \\
\text { digital core that will form the foundation of the new business model. }\end{array}$ \\
\hline
\end{tabular}

\subsection{Develop Target Enterprise Architecture}

ArchiSurance mapped the target core capabilities. The new architecture will transform the current core capabilities and add to them new capabilities as shown in figure 14:

\section{ArchiSurance Core Capabilities Diagram}

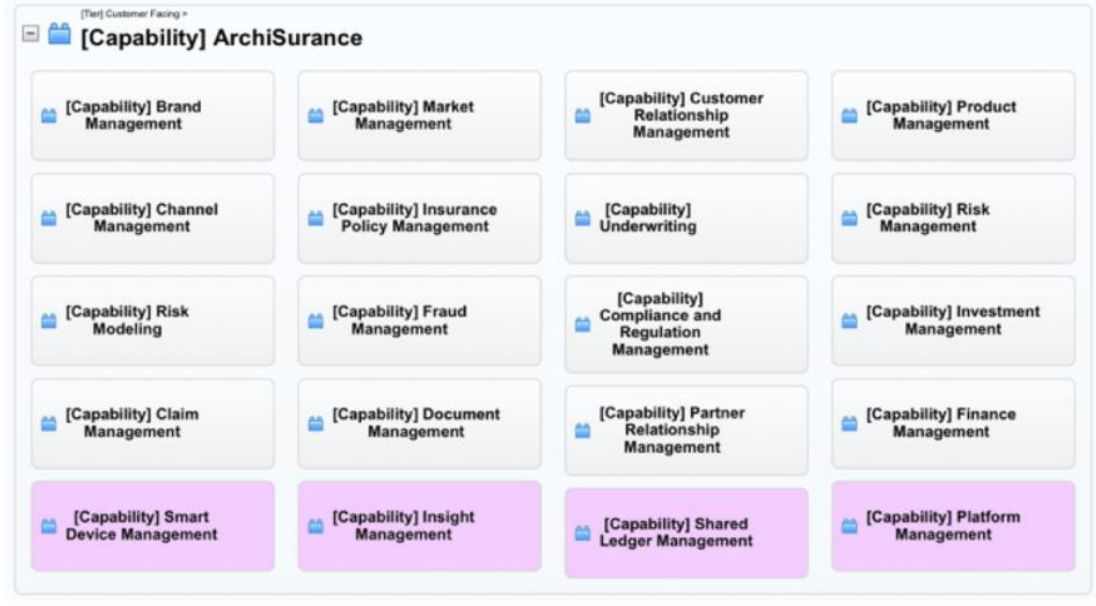

Figure 14. ArchiSurance Target Core Capabilities

The new digital core will be deployed as shown in figure 15: 


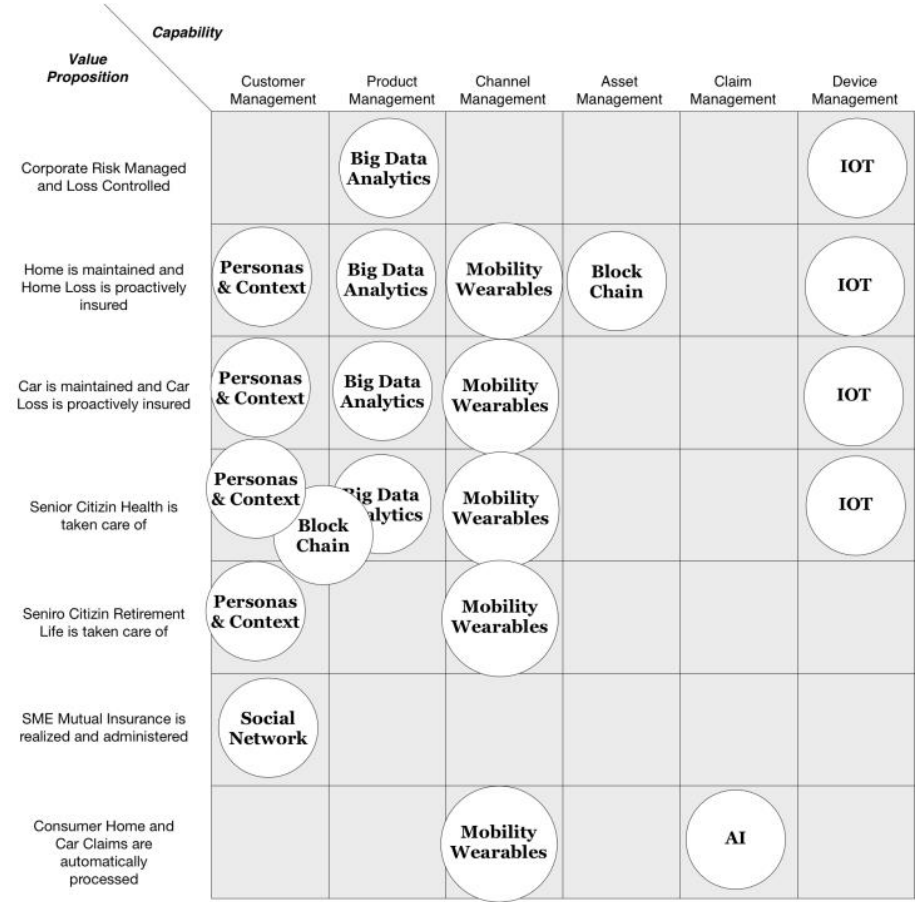

Figure 15. ArchiSurance Digital Technologies Deployment

ArchiSurance target application portfolio is shown in figure 16:
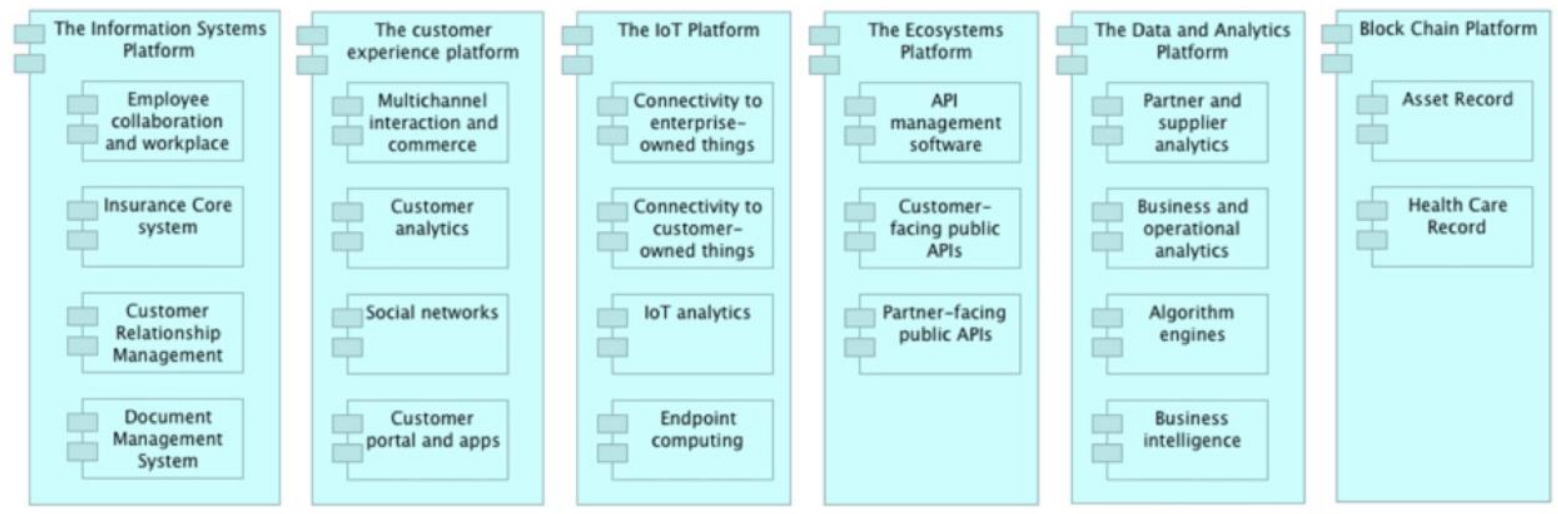

Figure 16. ArchiSurance Target Application Portfolio

\subsection{Implement Resilience Transformation Programme}

ArchiSurance created a transformation programme including the following initiatives (figure 17): 


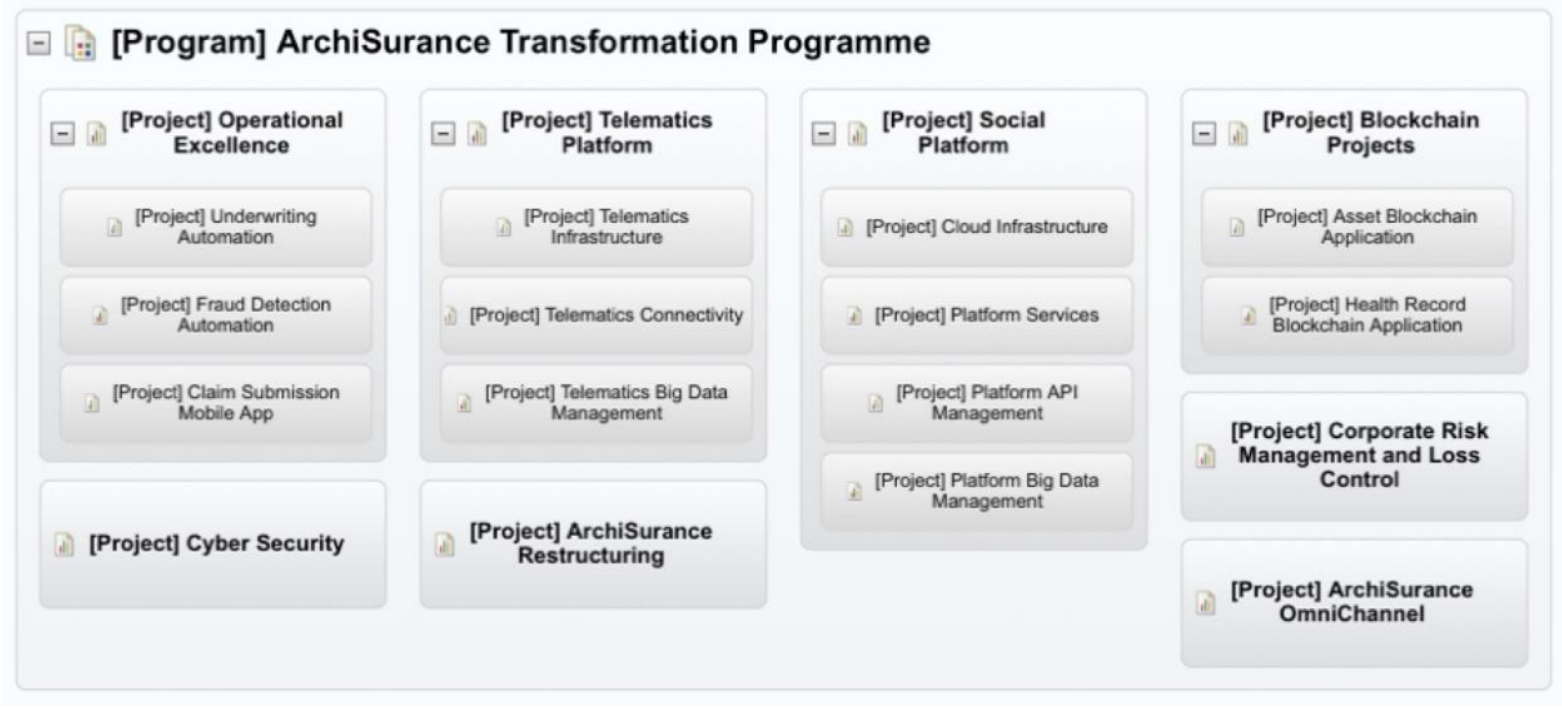

Figure 17. ArchiSurance Transformation Programme

\section{Conclusions and Future Work}

In this paper we propose an integrated resilience framework to guide business enterprises to design and implement the right changes when they are faced with game-changing strategic disruptions. To be an effective framework, it must fulfil a set of requirements including: the ability to monitor and interpret shifts in the environment, the ability to apply the operating efficiency scenario, the ability to apply the adaption scenario, the ability to apply the transformation scenario, the ability to articulate the core capabilities of the business enterprise, the ability to organize enterprise concepts into layers with different rate of change, and the ability to develop IT architecture that is business driven.

Since traditional strategic management approaches failed to address this problem, we had to choose a tool that is capable to steer the whole enterprise. So, we overlaid the framework over a combination of two frameworks, the enterprise architecture framework and the business architecture framework. The two frameworks can be combined and integrated together perfectly in a way that addresses the requirements of the framework. The framework is composed of two main components: the enterprise resilience architecture development method and the enterprise resilience architecture meta-model.

There are several limitations to the work we have presented. We have stated that the framework can integrate with other domains like strategic management and enterprise risk management. Therefore, we suggest that further research should be done in order to elaborate more on the possibility of these collaborations. Also, we have demonstrated our proposed framework with the help of one case study. Although this is sufficient for stating that our approach is viable for the organisation under analysis, we cannot state that it is applicable for all organisations. Therefore, further research needs to be done in order to investigate the generalizability of our framework. 


\section{References}

Barney, J. B. (1991). Firm Resources and Sustained Competitive Advantage. Journal of Management, 17, 99-120. https://doi.org/10.1177/014920639101700108

Bernard, S. A. (2012). An introduction to enterprise architecture. AuthorHouse.

Bossidy, L., \& R. Charan (2002). Execution, The Discipline of Getting Things Done Crown Business. New York.

Brandenburger, A. M., \& H. W. Stuart (1996). Value - based business strategy. Journal of $\begin{array}{llll}\text { economics } \quad \& \quad \text { management } & \text { strategy, } & 5(1), & 5-24 .\end{array}$ https://doi.org/10.1111/j.1430-9134.1996.00005.x

Burton, B. (2010). Eight Business Capability Modeling Best Practices. Gartner Research, ID(G00175782).

Choo, C. W. (1996). The knowing organization, How organizations use information to construct meaning, create knowledge and make decisions. International Journal of Information Management, 16(5), 329-340. https://doi.org/10.1016/0268-4012(96)00020-5

De Jong, M., et al. (2013). The eight essentials of innovation performance. McKinsey Strategy.

Fehskens, L. (2008). Re-thinking architecture-the architecture of enterprise architecture. 20th Enterprise architecture practitioners conference. The Open Group, Reading, UK.

Fiksel, J. (2003). Designing Resilient, Sustainable Systems. Environmental Science and Technology, 37(23), 5330-5339. https://doi.org/10.1021/es0344819

Folke, C., et al. (2002). Resilience and sustainable development, building adaptive capacity in a world of transformations. Ambio, 31, 437-440. https://doi.org/10.1579/0044-7447-31.5.437

Folke, C., et al. (2010). Resilience Thinking, Integrating Resilience, Adaptability and Transformability. Ecology and 20. https://doi.org/10.5751/ES-03610-150420

Frow, P., \& A. Payne (2011). A stakeholder perspective of the value proposition concept. European journal of marketing, 45(1/2), 223-240. https://doi.org/10.1108/03090561111095676

Galal-Edeen (2008). Cairo University Strategy Formulation, an Architectonic View. Conference on Enhancing the Competitiveness of Universities, Faculty of Commerce, Cairo University.

Garr, D., \& I. Redux (2000). Lou Gerstner and the Business Turnaround of the Decade, HarperInformation. 
Geracie, G., \& S. D. Eppinger (2013). The Guide to the Product Management and Marketing Body of Knowledge, Product Management Educational Institute (PMEI).

GUILD, B. (2014). A Guide to the Business Architecture Body of Knowledge (BIZBOK Guide). V04.

Hamel, G., \& L. Välikangas (2003). The Quest for Resilience. Harvard Business Review.

Holling, C. S. (1973). Resilience and Stability of Ecological Systems. Annual Review of Ecological Systems, 4. https://doi.org/10.1146/annurev.es.04.110173.000245

Jonkers, H., et al. (2012). The ArchiSurance case study. White paper, The Open Group, Spring.

Josey, A. (2011). Togaf version 9.1 enterprise edition, An introduction, Open Group.

Josey, A., et al. (2016). An Introduction to the ArchiMate ${ }^{\circledR}$ 3.0 Specification. White Paper from The Open Group.

Kellerman, J., \& P. Löfgren (2008). Application Portfolio Management.

Komori, S. (2015). Innovating out of crisis, How Fujifilm survived (and Thrived) as its core business was vanishing. Stone Bridge Press, Inc.

Lankhorst, M. (2009). \{Enterprise Architecture at Work, Modelling, Communication and Analysis (The Enterprise Engineering Series)\}.

Lapkin, A., et al. (2008). Gartner Clarifies the Definition of the Term Enterprise Architecture. Research G00156559, Gartner.

Longstaff, P. H., et al. (2010). Building Resilient Communities, A Preliminary Framework for Assessment. HOMELAND SECURITY AFFAIRS VI(3).

May, R. M., et al. (2008). Complex systems, Ecology for bankers. Nature, 451(7181), 893-895. https://doi.org/10.1038/451893a

Peffers, K., et al. (2007). A design science research methodology for information systems research. Journal of management information systems, 24(3), 45-77. https://doi.org/10.2753/MIS0742-1222240302

Quinn, J. B. (1980). Strategies for change, Logical incrementalism. Irwin Professional Publishing.

Reeves, M., et al. (2016). The biology of corporate survival. Harvard Business Review, 94(1), 2.

Schwartz, P., \& D. Randall (2007) Ahead of the Curve, Anticipating Strategic Surprise. MONITOR_GROUP

Ulrich, W., \& M. Rosen (2014). The Business Capability Map, Building a Foundation for Business/IT Alignment (2011). Cutter Consortium for Business and Enterprise Architecture. 
Walker, B., \& J. A. Meyers (2004). Thresholds in Ecological and Social-Ecological Systems, a Developing Database. Ecology and Society, 9(2), 3. https://doi.org/10.5751/ES-00664-090203

Winter, R., \& R. Fischer (2006). Essential layers, artifacts, and dependencies of enterprise architecture. Enterprise Distributed Object Computing Conference Workshops, 2006. EDOCW'06. 10th IEEE International, IEEE. https://doi.org/10.1109/EDOCW.2006.33

Yoder, J., et al. (2012). Insurance 2020, Turning change into opportunity, Retrieved from Pricewaterhouse-Coopers website, http//www.pwc.com/gx/en/insurance/pdf/insurance-2020-turning-change-into-opportunit y.pdf.

\section{Copyright Disclaimer}

Copyright for this article is retained by the author(s), with first publication rights granted to the journal.

This is an open-access article distributed under the terms and conditions of the Creative Commons Attribution license (http://creativecommons.org/licenses/by/3.0/). 